\title{
Induction of Tumor Cell Apoptosis by a Proteasome Deubiquitinase Inhibitor Is Associated with Oxidative Stress
}

\author{
Slavica Brnjic, Magdalena Mazurkiewicz, Mårten Fryknäs, ${ }^{1}$ Chao Sun, Xiaonan Zhang, ${ }^{1}$ \\ Rolf Larsson, ${ }^{2}$ Pádraig D'Arcy, and Stig Linder ${ }^{1,2}$
}

\begin{abstract}
Aims: b-AP15 is a recently described inhibitor of the USP14/UCHL5 deubiquitinases (DUBs) of the 195 proteasome. Exposure to b-AP15 results in blocking of proteasome function and accumulation of polyubiquitinated protein substrates in cells. This novel mechanism of proteasome inhibition may potentially be exploited for cancer therapy, in particular for treatment of malignancies resistant to currently used proteasome inhibitors. The aim of the present study was to characterize the cellular response to b-AP15-mediated proteasome DUB inhibition. Results: We report that b-AP15 elicits a similar, but yet distinct, cellular response as the clinically used proteasome inhibitor bortezomib. b-AP15 induces a rapid apoptotic response, associated with enhanced induction of oxidative stress and rapid activation of Jun-N-terminal kinase 1/2 (JNK)/activating protein-1 signaling. Scavenging of reactive oxygen species and pharmacological inhibition of JNK reduced b-AP15-induced apoptosis. We further report that endoplasmic reticulum (ER) stress is induced by b-AP15 and is involved in apoptosis induction. In contrast to bortezomib, ER stress is associated with induction of $\alpha$-subunit of eukaryotic initiation factor 2 phosphorylation. Innovation: The findings establish that different modes of proteasome inhibition result in distinct cellular responses, a finding of potential therapeutic importance. Conclusion: Our data show that enhanced oxidative stress and ER stress are major determinants of the strong apoptotic response elicited by the 19S DUB inhibitor b-AP15. Antioxid. Redox Signal. 21, 2271-2285.
\end{abstract}

\section{Introduction}

$\mathbf{T}$ HE UBIQUiTIN PROTEASOME SYSTEM (UPS) is the major intracellular protein degradation system in eukaryotic cells (23). Ubiquitin is a conserved 76-amino-acid protein that is covalently attached to target proteins via a series of enzymatic steps, resulting in the trafficking of tagged proteins to the $26 \mathrm{~S}$ proteasome. The $26 \mathrm{~S}$ proteasome complex functions as the cell's molecular shredder and consists of a proteolytic $20 \mathrm{~S}$ core particle (20SCP) that is associated with one or two $19 \mathrm{~S}$ regulatory particles (19SRPs) (23). The 19SRP binds polyubiquitin-tagged proteins and promotes substrate translocation into the catalytic chamber where protein degradation is mediated by the chymotrypsin-like, trypsin-like, and peptidylglutamyl peptide hydrolyzing activities of the 20SCP (18).

The efficient degradation of ubiquitinated substrates requires both unfolding and removal of polyubiquitin chains.

\section{Innovation}

Although proteasome inhibitors are effective for treatment of multiple myeloma, resistance eventually develops. The small molecule b-AP15 inhibits proteasomal degradation by inhibiting the USP14/UCHL5 deubiquitinases of the $19 \mathrm{~S}$ regulatory particle. Here, we show that b-AP15 induces a distinct cellular response compared with a $20 \mathrm{~S}$ core particle inhibitor. The potent apoptotic activity of bAP15 is associated with strong increases of chaperone expression and strong induction of oxidative stress. Further, we show that inhibition of PKR-like ER kinase activation during endoplasmic reticulum stress is not essential for the cytotoxicity of proteasome inhibitors. The finding that different modes of blocking proteasome function induce distinct cellular responses has therapeutic implications.

\footnotetext{
${ }^{1}$ Department of Oncology and Pathology, Cancer Center Karolinska, Karolinska Institute, Stockholm, Sweden.

${ }^{2}$ Division of Clinical Pharmacology, Department of Medical Sciences, Uppsala University, Uppsala, Sweden.
} 
The translocation of ubiquitin-tagged proteins into the proteolytic core is facilitated by the deubiquitinase (DUB) activity of the 19SRP. In the absence of deubiquitination, bulky ubiquitin moieties would impede entry of the substrate into the 20SCP chamber. DUBs cleave the isopeptide bonds between the C-terminal carboxyl of ubiquitin and the amino group of a lysine residue on an adjacent protein and salvage ubiquitin for reuse by the UPS (23). The 19SRPs of metazoan cells are associated with three different DUBs. USP14 and UCH37/ UCHL5 are cysteine isopeptidases that cleave distal polyubiquitin chains and are suggested to promote substrate rescue rather than degradation (33). The third DUB of the 19SRP is the RPN11/POH1 metalloprotease, a $\mathrm{Zn}^{2+}$-dependent protease of the JAMM family that is localized within the lid of the 19SRP. RPN11/POH1 performs ubiquitin chain amputation by cleaving entire chains from substrates in a process that is tightly coupled to degradation $(60,64)$.

Ubiquitinated proteins initially bind to the 195 subunits Rpn10 and Rpn13, but substrate entry requires interactions between polyubiquitin chain and the 19SRP DUBs $(21,50)$. Binding of polyubiquitin chains to USP14 (Ubp6 in yeast) promotes opening of the gate to the $20 \mathrm{SCP}$ (50). It was recently shown that substrate deubiquitination is coupled to stimulation of the activities of the AAA + ATPases in the base of the 19SRP that unwind protein substrates (51). Thus, binding of polyubiquitin conjugates to yeast Ubp6, or to USP14 and UCH37 in mammalian cells, leads to stimulation of 19SRP ATPase activity.

The dipeptidyl boronic acid bortezomib (PS-341, Velcade ${ }^{\circledR}$ ) is a selective inhibitor of the proteolytic activity of the 20SCP. Bortezomib has shown activity against several malignant cell types and has been approved by the US Food and Drug Administration as a first line treatment for patients with multiple myeloma (6). The downstream effects of proteasome inhibition that ultimately result in cell death are not completely understood. Proteasome inhibition generates a plethora of cellular responses, including inhibition of $\mathrm{NF} \kappa \mathrm{B}$ signaling (24), stabilization of Myc (45) and deregulation of Myc signaling (7), induction of endoplasmic reticulum (ER) stress (15), production of reactive oxygen species (ROS) $(15,36,49)$, and amino-acid depletion-induced autophagy (56).

A number of groups have reported that generation of cellular ROS is associated with proteasome inhibitor-induced cell death $(15,36,49)$. The interpretation of some of these studies is complicated by later findings of direct complex formation between proteasome inhibitor scavengers such as
$\mathrm{N}$-acetyl cysteine (NAC), vitamin $\mathrm{C}$, edaravone, and Tiron $(14,19,37,68)$. The role of oxidative stress in the induction of apoptosis and cell death is, therefore, somewhat controversial. The mechanism(s) of how ROS is induced in cells exposed to proteasome inhibitors are also unclear.

The ubiquitin system is believed to be highly druggable, but has been underexplored by drug developers (8). We recently identified b-AP15 as an inhibitor of the USP14 and UCHL5 DUBs of the 19SRP (10). Inhibition of both USP14 and UCHL5 leads to a functional block of the proteasome (32) and we, indeed, observed accumulation of various proteasomal substrates in cells exposed to b-AP15 (10). Since b-AP15 blocks the proteasome by a distinct mechanism to that of the clinically used agent bortezomib, it is conceivable that b-AP15 (or an optimized lead) could be used for treatment of multiple myeloma patients who have developed resistance to bortezomib. Our previous studies showed that b-AP15 and bortezomib differ with regard to the apoptotic responses that are elicited. We found that apoptosis by b-AP15, but not by bortezomib, was insensitive to the overexpression of $\mathrm{Bcl}-2$ and genetic disruptions of BAX and TP53 (10). These results were not expected from models in which apoptosis induction by proteasome inhibitors is due to stabilization of various proteasomal substrates such as IkB $(24,55)$, p53 (63), the proapoptotic proteins Bid and Bax (5,35), and Myc (45). To understand and characterize the mechanisms of b-AP15induced cytotoxicity, we have delineated the various cellular stress pathways affected. We report that disruption of redox homeostasis and induction of high levels of ROS is a major difference between the cellular responses to b-AP15 and bortezomib.

\section{Results \\ Proteasome inhibition by bortezomib and b-AP15 induces a similar stress response}

Proteasome inhibitors show a unique cytotoxic profile in the National Cancer Institute 60 cell line panel $\left(\mathrm{NCI}_{60}\right)$ when compared with thousands of other compounds (1). We compared the cytotoxic profiles of bortezomib (NSC681239) and b-AP15 (NSC687852) in the $\mathrm{NCI}_{60}$ panel, using data available in the NCI Developmental Therapeutics Program database (www.dtp.nci.nih.gov). A weak correlation of the sensitivities of the $\mathrm{NCI}_{60}$ cell lines to the two drugs was observed (Fig. 1A). Drugs in the NCI database have been assembled into selforganizing maps based on their cytotoxicity profiles, where

FIG. 1. b-AP15 and bortezomib induce similar but not identical cellular responses. (A) The $\mathrm{IC}_{50}$ values to b-AP15 (NSC687852) and bortezomib (NSC681239) of different cell lines in the $\mathrm{NCI}_{60}$ cell line panel are plotted. Each dot represents the $\mathrm{IC}_{50}$ values of the two drugs in one cell line. The result shows a weak, but statistically significant, correlation of the cytotoxic responses to the two drugs in the $\mathrm{NCI}_{60}$ cell line panel. Statistical analysis: Pearson correlation coefficient. (B) Selforganizing map of the $\mathrm{NCI}_{60}$ tumor cell line panel. Compounds segregate into six major response categories: mitosis (M); nucleic acid metabolism (S); metabolic stress and cell survival (Q); membrane function (N); kinases/phosphatases and oxidative stress (P); and four unexplored regions, R, F, J, and V (27). b-AP15 and bortezomib map to distinct regions of the Q-region. (C) mRNA abundance of 84 genes reported to respond to stress were quantified by real-time quantitative polymerase chain reaction. HCT116 cells were exposed to b-AP15 or bortezomib for $6 \mathrm{~h}$, RNA was extracted, and mRNA levels were determined after reverse transcription. The yellow dotted line shows a y/x slope of 1 ; a y/x slope 1.67 was observed for transcript levels of cells exposed to b-AP15/bortezomib. (D) Expression of various classes of genes in HCT116 cells exposed to b-AP15 or bortezomib as fold induction (red dots=b-AP15; blue dots = bortezomib). (E, F) Expression of specific genes after exposure of HCT116 cells to b-AP15 or bortezomib (fold induction). Blue: HSF-1-regulated genes, green: genes associated with oxidative stress; red: genes associated with ER stress. $\mathrm{IC}_{50}, 50 \%$ inhibitory concentration; NCI, National Cancer Institute; HSF-1, heat shock factor protein 1. 
the position of a particular drug reflects its main mechanism of action (52). The majority of clinically used cancer therapeutics map to the " $\mathrm{M}$ " and " $\mathrm{S}$ " areas, where " $\mathrm{M}$ " represents agents that interfere with mitosis and " $\mathrm{S}$ " represents agents which interfere with nucleic acid synthesis. Bortezomib and b-AP15 map to distinct subregions of the "Q" area, associated with metabolic stress (Fig. 1B). These results suggest that bortezomib and b-AP15 display related, yet distinct, mechanisms of action.
We previously reported that b-AP15 treatment induces a gene expression profile related to that of several characterized proteasome inhibitors (10). We extended this analysis to a subset of stress responsive genes that are commonly affected by chemotherapeutical reagents. Colon carcinoma cells were used, as these are known to be sensitive to b-AP15 (10). HCT116 colon carcinoma cells were exposed to b-AP15 or bortezomib at $\mathrm{IC}_{90}$ concentrations, and gene expression was determined by quantitative polymerase chain reaction

B
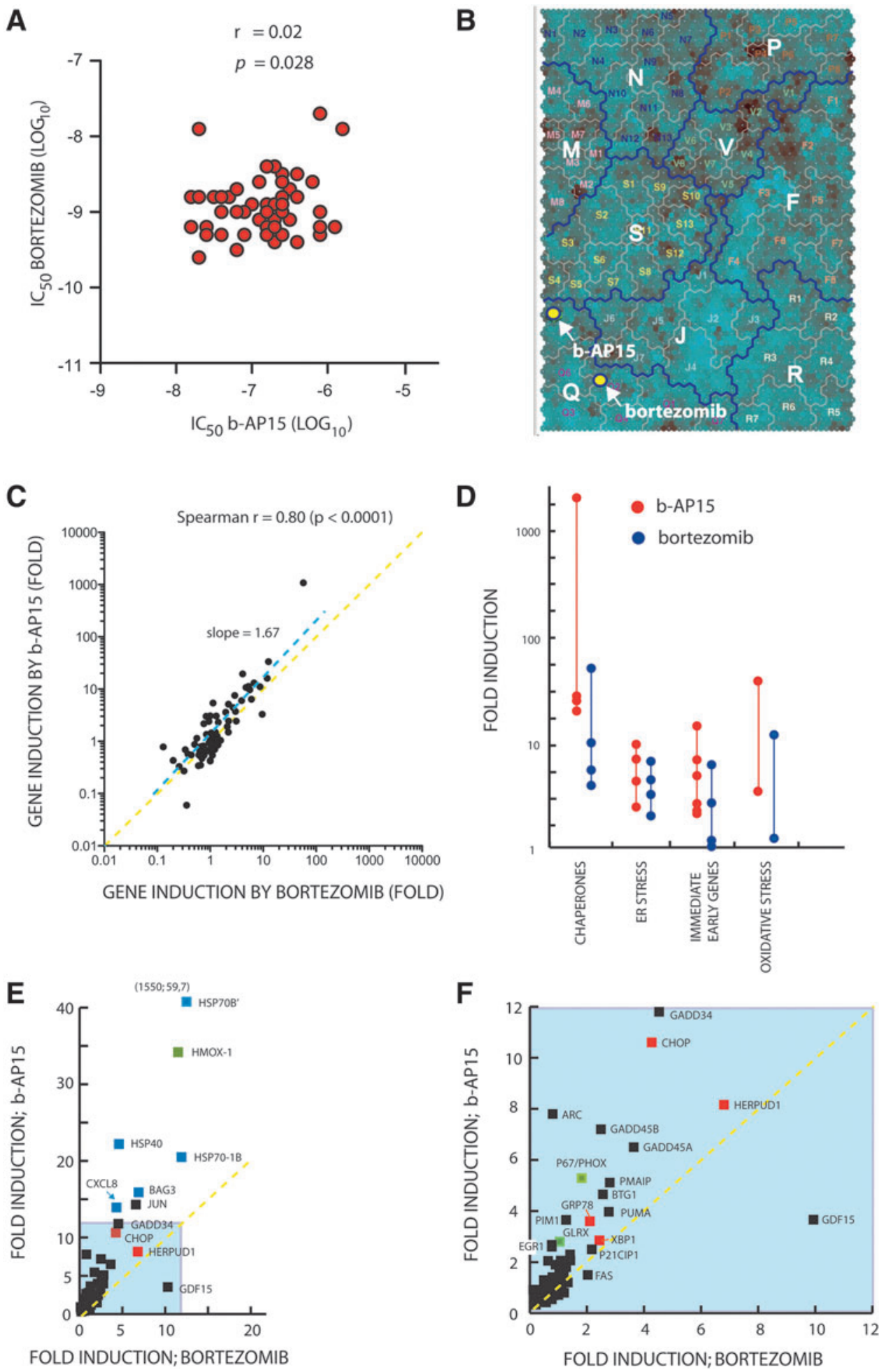
(qPCR). Both drugs induced a similar pattern of expression of an 84 gene set (Spearman $r=0.80, p<0.0001$; Fig. 1C), with genes associated with oxidative stress, ER stress, heat shock, and the immediate early response displaying major alterations in gene expression (Fig. 1D). However, the amplitude of activation of several genes was higher in b-AP15-exposed cells (best-fit slope $=1.67$ ). The most conspicuous difference in the response to b-AP15 and bortezomib was the $>1000$-fold induction of HSPA6 by b-AP15 (Fig. 1E). HSPA6 encodes the Hsp70B' protein, a heat-shock induced chaperone that acts as the cells' final defense against proteotoxicity (46). Genes regulated by heat shock factor-1, mostly chaperone genes, were in general more strongly induced by b-AP15 when compared with bortezomib (Fig. 1E, blue boxes). Both b-AP15 and bortezomib increased the expression of genes associated with oxidative stress; however, the induction of HMOX 1 and $P H O X / p 67$ expression was $\sim 2.5$-fold stronger in b-AP15- compared with bortezomib-exposed cells (Fig. 1E, F; green boxes). The expression of immediate early response genes such as JUN, GADD34, GADD45A, and GADD45B were also more strongly induced by b-AP15 compared with bortezomib (Fig. 1E, F). Finally, similar increases in the expression of genes associated with ER stress were observed after treatment with either drug (Fig. 1E, F; red boxes). We conclude that the two drugs induce similar cellular responses; however, b-AP15 elicited a stronger induction of chaperone genes, genes associated with oxidative stress, and immediate early response genes compared with bortezomib.

\section{Inhibition of proteasome function precedes apoptosis after exposure to the DUB inhibitor b-AP15}

Cytotoxicity of b-AP15 to tumor cells is associated with induction of apoptosis (10). Analysis of the kinetics of apoptosis induction showed that b-AP15 elicited a more rapid induction of caspase-cleavage of the endogenous cellular substrate keratin-18 (K18) compared with bortezomib (Fig. $2 \mathrm{~A})$, with high levels of cleaved K18 appearing $16 \mathrm{~h}$ post drug treatment. We previously reported that b-AP15 induces apoptosis in tumor cells genetically defective in $B A X$ and in cells overexpressing Bcl-2 (10). Bax and Bak are essential for induction of cytochrome c release from mitochondria during apoptosis (62). To extend our previous findings, we used siRNA to down- regulate the expression of Bak in HCT116 colon carcinoma cells. As shown in Figure 2B, down-regulation of Bak did not affect apoptosis induction by b-AP15, but inhibited apoptosis induced by bortezomib. The conformation of Bak is altered during apoptosis, resulting in increased accessibility of antibodies binding to the N-terminal domain (17). Treatment of HCT116 cells with b-AP15 resulted in increased antibody binding to Bak, indicating conformational activation (Fig. 2C). This activation does not, however, appear to be required for b-AP15-induced apoptosis, presumably due to the activation of parallel apoptotic signaling pathways.

We next examined the effects of b-AP15 on in vivo proteasome function using a reporter cell line, MelJuSo, expressing the proteasome targeted fusion substrate $\mathrm{Ub}^{\mathrm{G} 76 \mathrm{~V}}$-yellow fluorescent protein (YFP) (40). This substrate is intrinsically unstable due to constitutive degradation by the proteasome; thus, impairment of the UPS leads to an increased fluorescent signal. At doses below the $\mathrm{IC}_{50}(0.25 \mu \mathrm{M})$, a small number of cell nuclei displayed YFP positivity after $1-3 \mathrm{~h}$ of b-AP15 drug exposure (Fig. 2D; Supplementary Movie S1 and S2; Supplementary Data are available online at www.liebertpub.com/ ars). During the observation period, only these positive cells subsequently rounded up and died. The link between proteasome inhibition and cell death was confirmed using tetramethylrhodamine ethyl ester (TMRE; a fluorescent probe used to monitor the membrane potential of mitochondria), which showed that YFP accumulation preceded loss of mitochondrial membrane potential (Fig. 2E).

\section{b-AP15 induces ER stress}

The up-regulation of genes involved in the ER stress response by b-AP15 (Fig. 1D-F) is consistent with previous reports showing induction of ER stress by bortezomib $(15,44)$. As shown in Figure 3A, b-AP15 induced the expression of the ER chaperone Grp78 (BiP) in HCT116 cells. The level of induction was similar to that observed with bortezomib, but weaker than the response to the ER stress-inducer thapsigargin, an inhibitor of sarcoendoplasmic $\mathrm{Ca}^{2+}$ ATPase. b-AP15 induced phosphorylation of $\alpha$-subunit of eukaryotic initiation factor $2(\mathrm{eIF} 2-\alpha)$ already at $6 \mathrm{~h}$ post-drug treatment (Fig. 3A). Phosphorylation of eIF2- $\alpha$ is an integral part of the unfolded protein response, by decreasing the load of

FIG. 2. b-AP15-induced apoptotic signaling is distinct from that of bortezomib and apoptosis is preceded by proteasome inhibition. (A) Induction of caspase-cleavage activity by b-AP15 and bortezomib. (Upper panel) HCT116 cells were treated with $1 \mu \mathrm{M}$ b-AP15 or $100 \mathrm{n} M$ bortezomib for the times indicated, and ccK18 was determined in the cells and medium by the M30 CytoDeath ELISA (Peviva AB). (Lower panel) Dose response to b-AP15 and bortezomib; ccK18 was determined at $24 \mathrm{~h}$ by ELISA. The pan-caspase inhibitor z-VAD-fmk totally inhibits increases of the signal (see Fig. 3C); (B) HCT116 cells were transfected with an siRNA to BAK or a scrambled control siRNA and incubated for $48 \mathrm{~h}$. Cells were treated with either drug or DMSO solvent and processed for western blotting (top) or M30 CytoDeath ELISA (bottom). Note the insensitivity to b-AP15-induced apoptosis of cells where Bak expression has been knocked down. (C) Activation of the conformation of Bak by b-AP15. Cells were treated for $6 \mathrm{~h}$, fixed, stained with an antibody to the Bak N-terminus, and analyzed by flow cytometry. Gray shaded area: vehicle-treated cells; non-shaded area: b-AP15-treated cells. (D) Analysis of accumulation of a proteasometargeted fusion protein $\left(\mathrm{Ub}^{\mathrm{G} 76 \mathrm{~V}}-\mathrm{YFP}\right)$ in MelJuSo cells after exposure to a low dose $(0.25 \mu M) \mathrm{b}$-AP15. Note the appearance of YFP in the nuclei of the MelJuSo cells at 1-3 h. Also note that all YFP-positive cells die during the period of observation, whereas cells not becoming YFP positive are unaffected. (E) Analysis of mitochondrial membrane potential $(\Delta \Psi)$ and accumulation of $\mathrm{Ub}^{\mathrm{G} 76 \mathrm{~V}}$-YFP in MelJuSo cells after treatment with $1 \mu M$ b-AP15. $\Delta \Psi$ was determined by staining with TMRE. Cells were analyzed by flow cytometry. Note that YFP positivity precedes the loss of $\Delta \Psi$ (staining with TMRE), showing that proteasome blocking occurs before commitment to apoptosis. ccK18, caspase-cleaved keratin 18; z-VAD-fmk, z-Val-Ala-Aspfluoromethylketone; ELISA, enzyme-linked immunosorbent assay; BAK, BCL2-antagonist/killer; DMSO, dimethyl sulfoxide; YFP, yellow fluorescent protein; TMRE, tetramethylrhodamine ethyl ester. 
misfolded proteins in the ER (22), and decreasing translation of cyclin D1 (20). In accordance with previous findings (44), bortezomib failed to induce phosphorylation of eIF2- $\alpha$. This is due to inhibition of PKR-like ER kinase (PERK) by bortezomib and leads to a lack of translational suppression, and was suggested to be important for the cytotoxic activity of bortezomib (44). The difference between b-AP15 and bortezomib to induce eIF2- $\alpha$ phosphorylation was verified in three additional colon cancer cell lines, whereas a fourth cell line (OXCO-1) displayed some induction by bortezomib (Fig. 3B). The underlying mechanism(s) of the variations in the response of the cell lines to b-AP15 and bortezomib was not examined further. We conclude that the rapid apoptotic response of HCT116 cells to b-AP15 occurs despite the induction of phosphorylation of eIF2- $\alpha$.

The ER-associated pro-caspase- 4 is the human homolog of mouse caspase-12 (43), and is cleaved after acute ER stress $(26,44)$. Caspase- 4 cleavage was detected in a time-dependent manner after bortezomib and b-AP15 treatment (Fig. 3A). To investigate the role of caspase- 4 in induction of apoptosis, HCT116 cells were exposed to the caspase-4 inhibitor ZLeu-Glu-Val-Asp-FMK or transfected with caspase-4 siRNA
A
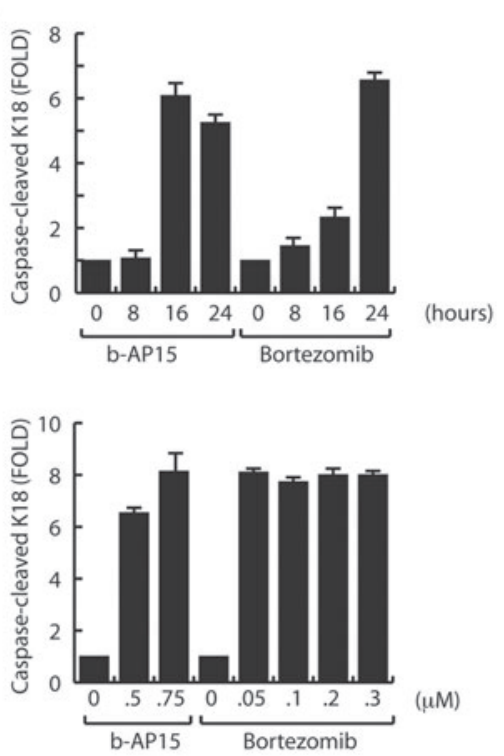

C

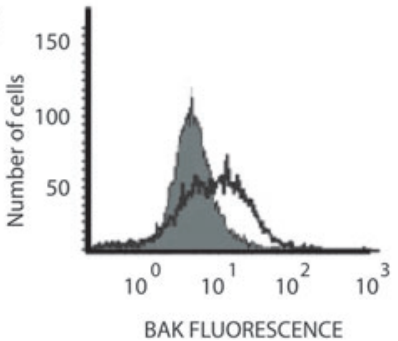

$\mathbf{E}$

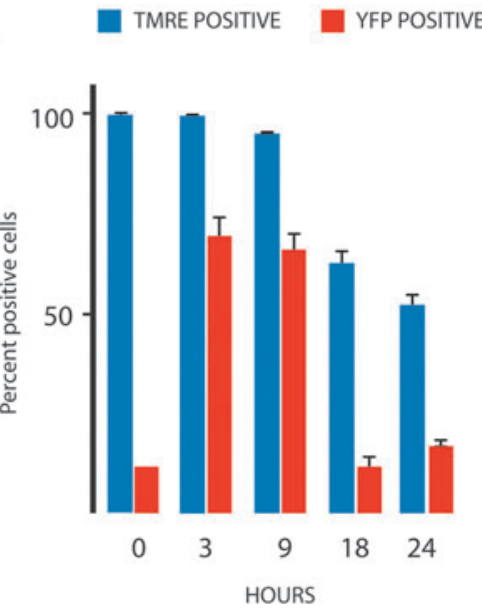

B
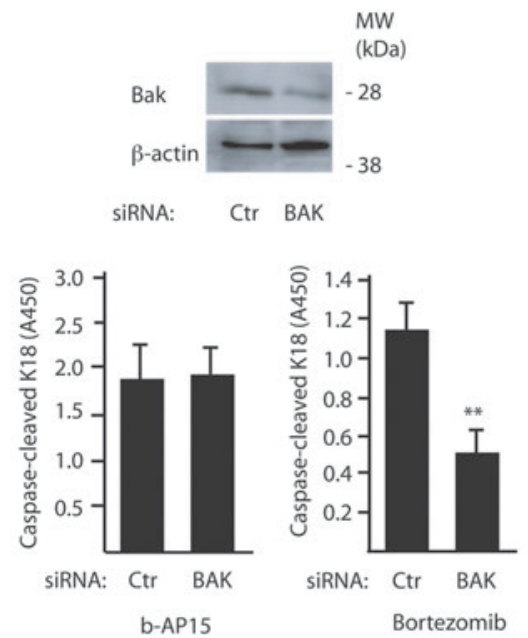

D
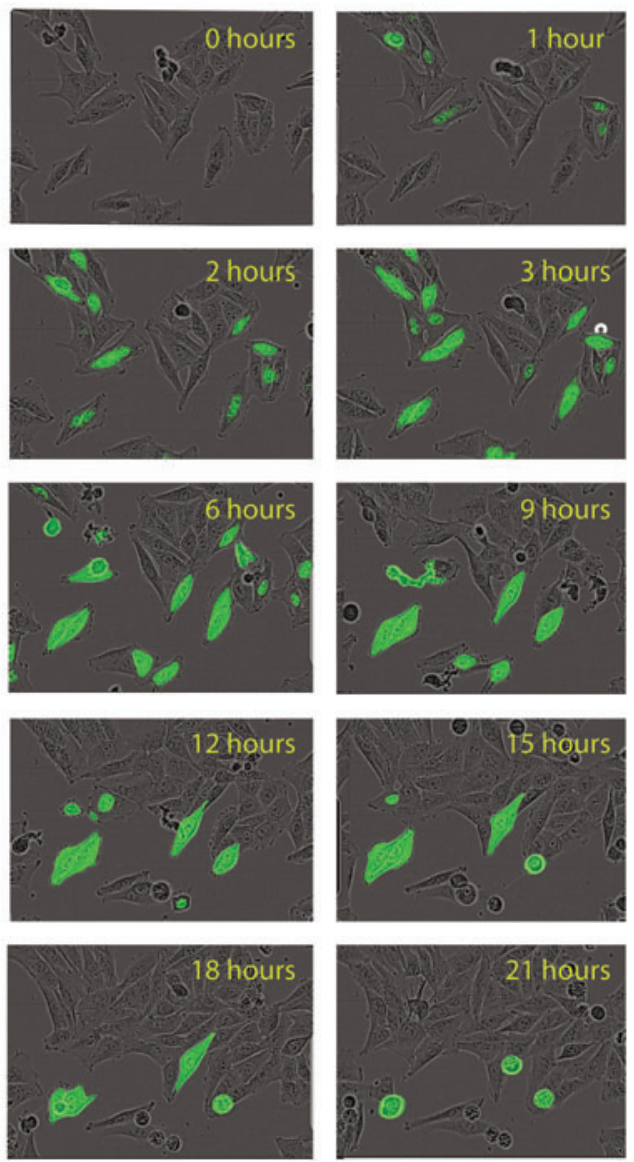
A

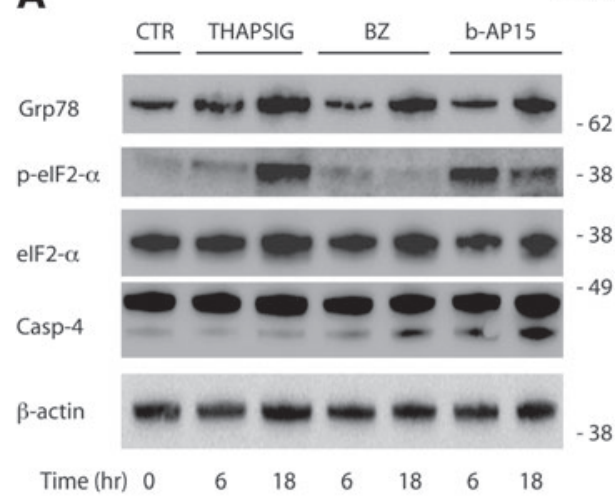

\section{(2)}

MW (kDa) 38 8
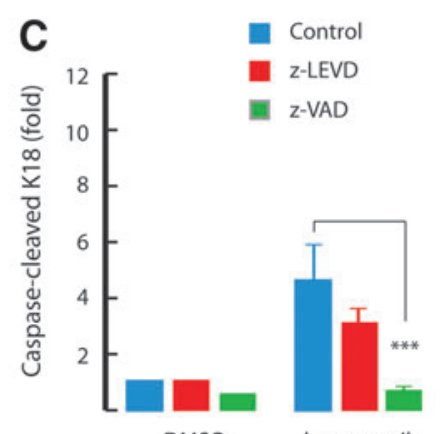

DMSO bortezomib
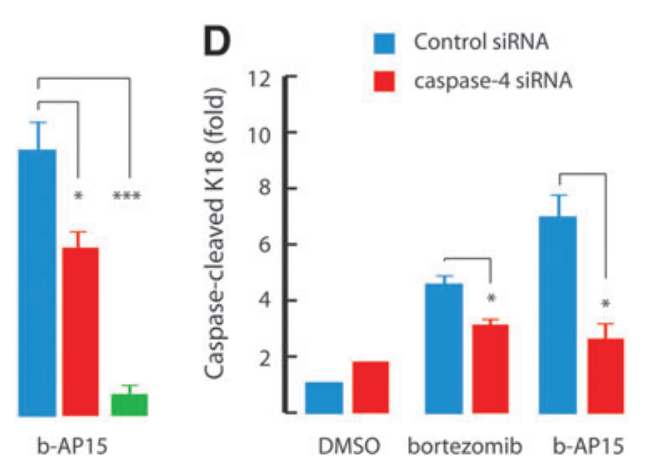

FIG. 3. b-AP15 induces endoplasmic reticulum stress. (A) HCT116 cells were exposed to $10 \mu M$ thapsigargin (an inhibitor of the sarco/endoplasmic reticulum Ca2 + ATPase), $100 \mathrm{nM}$ bortezomib (BZ), or $1 \mu \mathrm{M}$ b-AP15 and processed for western blotting. Note the similar induction of Grp78 by all treatments but the differences in induction of eIF2- $\alpha$ phosphorylation. (B) Induction of eIF2- $\alpha$ phosphorylation in CC20, OX-CO-1, CCO-7, and SW-620 colon carcinoma cells. Cells were treated for $6 \mathrm{~h}$ as indicated and processed for western blotting. (C, D) b-AP15-induced apoptosis is inhibited by the caspase-4 inhibitor z-LEVD and by caspase-4 siRNA. Transfection with siRNA was performed $48 \mathrm{~h}$ before addition of drugs, the caspase- 4 inhibitor z-LEVD (20 $\mu M)$ or the pan-caspase inhibitor z-VAD $(50 \mu M)$ were added at the same time as $100 \mathrm{n} M$ bortezomib or $1 \mu M$ b-AP15. Caspase-cleaved K18 was measured by ELISA at $24 \mathrm{~h}$ after drug addition; downregulation of caspase- 4 was verified by western blotting. Grp78, glucose-regulated protein 78; eIF2- $\alpha$, eukaryotic initiation factor 2 alpha; z-LEVD, Z-Leu-Glu-Val-Asp-FMK.

and exposed to either bortezomib or b-AP15. Quantification of the levels of caspase-cleaved K18 showed that inhibition of, or depletion of, caspase- 4 reduced both bortezomib- and bAP15-induced apoptosis (Fig. 3C, D). Taken together, our data suggest that the ER stress induced by b-AP15 contributes to its apoptotic potential.

\section{Role of ROS in b-AP15-induced apoptosis}

ROS production has been reported to be a critical mediator of bortezomib-induced apoptosis $(15,36,49)$. The strong induction of HMOX1 (Fig. 1E), a target gene of redox-regulated nuclear factor-erythroid-2-related factor 2 (Nrf-2), by b-AP15 is consistent with induction of oxidative stress. Induction of HMOX1 gene expression by b-AP15 in HCT116 cells was confirmed at the protein level by western blotting (Fig. 4A). In MelJuSo $\mathrm{Ub}^{\mathrm{G} 76 \mathrm{~V}}$-YFP cells, Hmox-1 expression was not further increased using higher concentrations $(250 \mathrm{nM})$ of bortezomib (Fig. 4B). The difference in induction of Hmox-1 by bortezomib and b-AP15 was, therefore, not due to the use of insufficient concentrations of bortezomib.

Experiments using the fluorescent ROS probe $2^{\prime}, 7^{\prime}$ dichlorofluorescin diacetate (DCFH-DA) confirmed that b-AP15 induces higher levels of ROS compared with bortezomib (Fig. 5A). To investigate whether ROS was involved in
b-AP15-induced apoptosis, we treated HCT116 cells with the water-soluble vitamin $\mathrm{E}$ derivative and antioxidant Trolox. Trolox inhibited apoptosis by $\sim 50 \%$ (Fig. 5B). In these experiments, cells were pulsed with b-AP15 for $1 \mathrm{~h}$, after which the drug was removed and fresh media containing Trolox were added. In contrast, no effect on apoptosis was observed when Trolox was present only during the time of drug incubation (Fig. 5B). NAC also inhibited apoptosis induction when added after removal of b-AP15 (Fig. 5C). The inhibitory effects of the ROS scavengers Trolox and NAC on apoptosis are, therefore, not due to a direct chemical reaction with b-AP15 as described for other UPS inhibitors (19), but rather to inhibition of ROS generation downstream from b-AP15mediated proteasome inhibition. However, when we analyzed the effect of Trolox on rescuing cells from ROS-induced death, no reduction in cytotoxicity was observed (Supplementary Fig. S1). This was in contrast to bortezomib, where Trolox partially inhibited drug-induced cell death (Supplementary Fig. S1). These findings show that apoptosis induction by b-AP15 involves oxidative stress, but that other mechanisms will eventually cause cell death when oxidative stress is alleviated.

Sustained oxidative stress is known to impair the functionality of the UPS $(9,13)$. The activity of the proteasome appears to be more sensitive to oxidative stress than the DUBs 
A
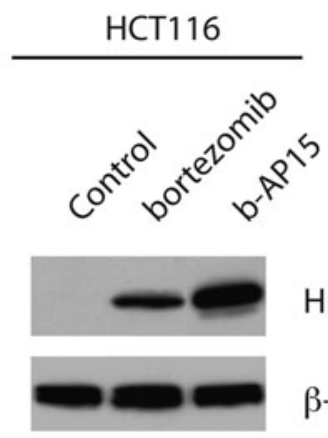

Hmox-1

$\beta-A C T$

B

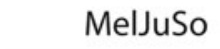

b-AP15 $(\mu \mathrm{M})$ bortezomib $(\mu \mathrm{M})$

$\begin{array}{llllllll}0.6 & 0.8 & 1 & 0.05 & 0.10 .150 .20 .25\end{array}$

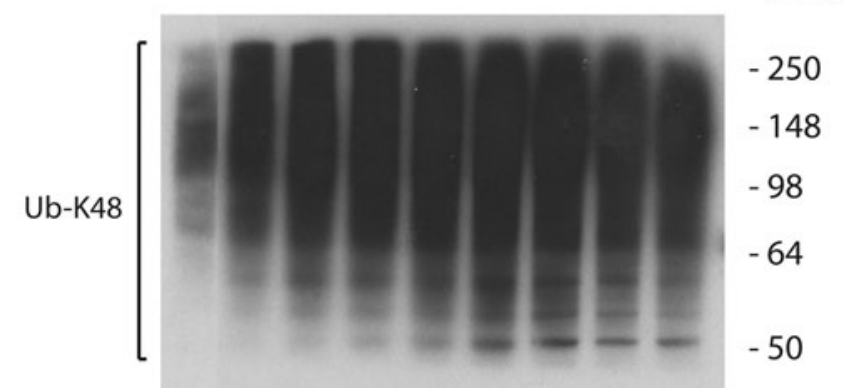

Ub-YFP

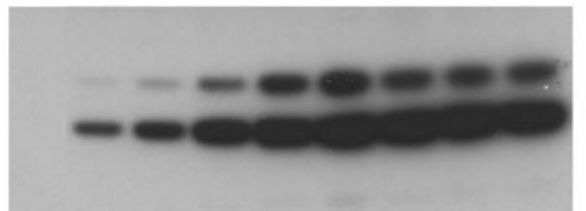

Hmox-1

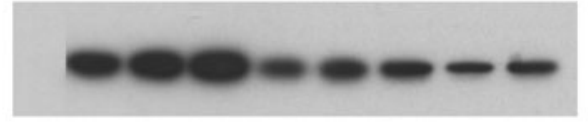

$\beta$-actin

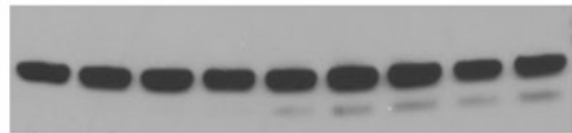

FIG. 4. Induction of Hmox-1 [heme oxygenase (decycling) 1] protein expression by b-AP15 and bortezomib. (A) HCT116 cells were exposed to $100 \mathrm{nM}$ bortezomib or $1 \mu \mathrm{M} \mathrm{b}$ $\mathrm{AP} 15$ for $18 \mathrm{~h}$ and processed for western blotting using antibodies to Hmox-1 or $\beta$-actin. (B) MelJuSo Ub ${ }^{\mathrm{G} 7 \mathrm{~V}}$-YFP cells were exposed to the indicated concentrations of bortezomib or b-AP15 for $18 \mathrm{~h}$ and processed for western blotting using antibodies to ubiquitin, Hmox-1, or $\beta$-actin. Note that the use of increasing concentration of bortezomib does not result in further induction of Hmox-1.

(66). The finding of strong induction of oxidative stress by b-AP15, therefore, raised the possibility that alterations in cellular redox status contribute to inhibition of proteasome function. To examine this question, we exposed MelJuSo $\mathrm{Ub}^{\mathrm{G} 76 \mathrm{~V}}$-YFP reporter cells to bortezomib or b-AP15 in the presence and absence of Trolox as an ROS scavenger (Fig. 5D). The presence of Trolox during the drug treatment had no effect on the accumulation of the $\mathrm{Ub}^{\mathrm{G} 76 \mathrm{~V}}$-YFP reporter, con- firming that both drugs inhibit proteasome activity independently of ROS levels (Fig. 5D). We also examined whether proteasome function was affected by rotenone, an agent that interferes with mitochondrial electron transport and induces ROS. No effect on $\mathrm{Ub}^{\mathrm{G} 76 \mathrm{~V}}$-YFP accumulation in cells was observed (Fig. 5D).

To investigate the biological effects of ROS induced by proteasome inhibition, we studied the effect of scavengers on gene expression after treatment with b-AP15. Pretreatment with Trolox resulted in a lower level of expression of a number of stress-induced genes after proteasome inhibition (Fig. 5E). As expected, the expression of the oxidative stress-induced genes HMOX1 and PHOX/p67 was reduced by cotreatment with Trolox. The induction of genes regulated by HSF-1 was also reduced; HSPA6 by approximately fivefold, HSPA1B and DNAJB1 (Hsp40) by approximately twofold. The reduction in chaperone expression after Trolox cotreatment may be due to alleviation of ROS-induced protein oxidation (2). The relationship between chaperone and ROS expression would fit with previous reports showing ROS induction of Hsp70 expression (39). Interestingly, b-AP15 induction of ER stress-regulated genes was not significantly affected by Trolox (Fig. 5E), suggesting that ER stress was independent from oxidative stress.

We finally examined the ability of a number of b-AP15 analogues to induce Hmox-1 and to induce the formation of high-molecular-weight poly-ubiquitin conjugates in HCT116 cells. We found that compound NSC687849 generated accumulation of poly-ubiquitin conjugates to a similar extent as b-AP15, whereas three other tested analogues did not show activity at $1 \mu M$ (Fig. 6). Interestingly, Hmox-1 levels were increased by b-AP15 and NSC687849, but not by the other compounds, showing an association between proteasomal blocking and induction of oxidative stress.

\section{Induction of stress-activated protein kinases}

We examined the gene expression response to b-AP15 in greater detail using Gene Set Enrichment Analysis (GSEA) of microarray data (54). Consistent with the qPCR results shown earlier, we found strong enrichment of genes containing HSF1-regulated promoters (Fig. 7A). Interestingly, the GSEA also showed a strong enrichment of genes regulated by the activating protein-1 (AP-1) transcription factor (Fig. 7B). Both b-AP15 and bortezomib induced induction of phosphorylation of Jun-N-terminal kinase 1/2 (JNK) in HCT116 cells (Fig. 7C). Phosphorylation of JNK could be detected at $1-2 \mathrm{~h}$ after exposure to b-AP15, time points when bortezomib did not induce JNK phosphorylation (Fig. 7C, D). Increasing the concentration of bortezomib to $1 \mu \mathrm{M}$ did not result in detectable induction of JNK phosphorylation at $2 \mathrm{~h}$ (Fig. 7D). At 6 and $8 \mathrm{~h}$, total c-Jun protein levels were increased in both bAP15- and bortezomib-treated cells (Fig. 7E), as expected from positive autoregulation (3). Increases in the phosphorylation of p38-MAPK were also observed after exposure to b-AP15 and to bortezomib (Supplementary Fig. S2A). Experiments using the JNK inhibitor SP600125 and the p38-MAPK inhibitor SB203580 showed that, as expected, stimulation of phosphorylation of c-Jun at Ser-73 was due to JNK activity (Fig. 7F). NAC was found to reduce JNK activation by b-AP15 in experiments in which the scavenger was added after removal of b-AP15 (Fig. 7G), suggesting that JNK activation was mediated by ROS. We finally examined whether activation of 
JNK and p38-MAPK was required for apoptosis induction by b-AP15 and bortezomib. Pharmacological inhibition of JNK was found to inhibit apoptosis induced by b-AP15 (Fig. 7H), whereas inhibition of p38-MAPK did not affect apoptosis (Supplementary Fig. S2B).

\section{Discussion}

The present study establishes that proteasome inhibition by the USP14/UCHL5 DUB inhibitor b-AP15 induces a distinct cellular response compared with that of the $20 \mathrm{~S}$ inhibitor bortezomib. The two agents elicit similar, but yet distinct, patterns of cytotoxicity on the $\mathrm{NCI}_{60}$ cancer cell line panel. Further, although both proteasome inhibitors induce apoptosis, the kinetics of b-AP15-induced caspase activation was significantly more rapid ( $>6 \mathrm{~h}$ time difference between treatments). The difference in the timing of apoptosis induction could not be explained by different kinetics of proteasome inhibition (Fig. 5D). Different apoptosis signaling pathways also appear to be induced in response to the two types of proteasome inhibitors, as b-AP15 does not require Bak or Bax for activation of caspase-cleavage activity [Fig. 2B and (10)]. The fact that the response to two agents both of which block the proteasome and that both increase the levels of proteins such as p53, p21, and p27 (10) differs raises questions with regard to the relative importance of stabilization of cellular regulatory proteins for triggering apoptosis. We hypothesize that the distinct cellular response to b-AP15 is related to the strong proteotoxic response induced by this drug, as evidenced by the $>1000$-fold induction of the HSPA6 chaperone gene by b-AP15. The mechanism underlying this elevated proteotoxicity is not clear but may be due to the accumulation of misfolded proteins with long polyubiquitin chains occurring as a consequence of inhibition of the USP14/UCHL5 DUBs (10). It is possible that misfolded proteins bearing longer ubiquitin chains are processed differently by the cell, resulting in stronger proteotoxic stress. Another possibility is that inhibition of other, non-proteasome-associated, activities of USP14 by b-AP15 will contribute to apoptosis induction [see (41)].

Oxidative stress has been associated with apoptosis induced by proteasome inhibitors $(15,36,49)$. While our results do not contribute to the understanding of why proteasome inhibitors induce oxidative stress, they clearly establish a role of ROS in the induction of apoptosis by b-AP15. Whether ROS is involved in apoptotic signaling in cells exposed to proteasome inhibitors is controversial, as a number of ROS scavengers such as NAC and vitamin C form complexes with bortezomib, piperlongumine, and other UPS inhibitors
$(14,19,37,68)$. Here, we found that b-AP15 induced an $\sim 40-$ fold induction of HMOX1 expression, a gene known to be regulated by Nrf-2 and induced in response to oxidative stress (42). The amplitude of HMOX1 induction by b-AP15 was significantly higher compared with bortezomib and was concomitant with ROS induction measured by DCFH-DA fluorescence. We found that apoptosis induction by b-AP15 was decreased by Trolox, whereas proteasome blocking was not impaired. By sequential exposure of cells to b-AP15 and scavengers (Trolox or NAC), we ascertained that inhibition of apoptosis by scavengers was not due to an interaction with the drug. Our findings, therefore, establish that ROS is a key mediator of apoptosis induction by b-AP15.

Oxidative stress is known to activate the stress-activated kinases p38-MAPK and JNK through ASK1 $(16,29)$, and these pathways are known to be induced by proteasome inhibitors $(25,65)$. Further, yeast strains carrying mutations in $26 \mathrm{~S}$ proteasome subunits overexpress Pap1, the Schizosaccharomyces pombe homolog of the human AP-1 transcription factor (48). We indeed found activation of both p38-MAPK and JNK by bAP15. Similar to previous reports on bortezomib $(25,65)$, a pharmacological inhibitor of JNK impaired b-AP15-induced apoptosis, whereas inhibition of p38-MAPK did not. As expected, phosphorylation of JNK was impaired by treatment with NAC. The relatively rapid induction of JNK implied that early induction of apoptosis is associated with activation of this pathway. These results establish JNK induction as a downstream mediator of b-AP15-induced oxidative stress.

Apoptosis by bortezomib has been attributed to the induction of ER stress $(11,15,44,58)$. b-AP15 was also found to induce ER stress as evidenced by increased expression of CHOP (CCAAT/enhancer-binding protein (C/EBP) homologous protein; GADD153), HERPUD1, GRP78, and XBP1 expression. $C H O P$ is known to be induced by ER stress and by oxidative stress (67). We found that the expression of ERstress responsive genes after b-AP15 was not affected by Trolox, showing that oxidative stress was not involved in mediating ER stress. A major difference in the ER stress response to b-AP15 and bortezomib was the induction of phosphorylation of the eIF2- $\alpha$ by b-AP15. eIF2- $\alpha$ is usually phosphorylated during ER stress by PERK, leading to attenuation of protein synthesis (31). Such translational attenuation will reduce protein synthesis and, thus, reduce accumulation of misfolded proteins in the ER (22), thereby alleviating ER stress and promoting cell survival. Bortezomib does not induce eIF2- $\alpha$ phosphorylation, due to inhibition of PERK, and the lack of attenuation of protein synthesis during ER stress has been

FIG. 5. b-AP15-induced apoptosis is inhibited by ROS scavengers. (A) Induction ROS by bortezomib or b-AP15 in HCT116 cells. Cells were stained with DCFH-DA after $6 \mathrm{~h}$ of treatment and analyzed by flow cytometry. (B) b-AP15-induced apoptosis is inhibited by the ROS scavenger Trolox. Cells were treated with $1 \mu M$ b-AP15 for $1 \mathrm{~h}$, and Trolox ( $5 \mathrm{~m} M)$ was added either during $(0-1 \mathrm{~h})$ or after $(1-24 \mathrm{~h})$ drug treatment. Caspase-cleaved K18 was determined by ELISA. (C) b-AP15induced apoptosis is inhibited by the ROS scavenger NAC. Cells were treated with $1 \mu \mathrm{Mb}$-AP15 for $1 \mathrm{~h}$, and $5 \mathrm{mM}$ NAC was added after drug treatment. Caspase-cleaved K18 was determined by ELISA after $24 \mathrm{~h}$. (D) Accumulation of Ub ${ }^{\mathrm{G} 76 \mathrm{~V}}-\mathrm{YFP}_{\mathrm{B}}$ in MelJuSo cells is not affected by Trolox. Cells were treated with $100 \mathrm{nM}$ bortezomib, $1 \mu \mathrm{M}$ b-AP15, or $50 \mu \mathrm{M}$ rotenone in the presence or absence of $5 \mathrm{mM}$ Trolox. Note the similar kinetics of induction of $\mathrm{Ub}^{\mathrm{G} 76 \mathrm{~V}}$-YFP in cells exposed to bortezomib or bAP15, and note the lack of effect of Trolox on YFP positivity. Rotenone induces strong induction of ROS in HCT116 cells (30) but does not induce YFP positivity. (E) Effects of Trolox on the expression of stress-associated genes. The expression of the 84 gene-set used in Figure 1 was examined in cells treated with b-AP15 in the presence or absence of 5 mM Trolox. Note the reduction of expression of genes regulated by HSF-1 and genes associated with oxidative stress in cells cotreated to Trolox, whereas genes associated with ER stress are not affected. ROS, reactive oxygen species; DCFH-DA, 2',7'-dichlorofluorescin diacetate; Trolox, 6-hydroxy-2,5,7,8-tetramethylchroman-2-carboxylic acid; NAC, N-acetyl cysteine. 
described as being important for the apoptotic activity of this agent (44). It is, therefore, interesting to note that b-AP15, which induces a more rapid induction of caspase cleavage activity compared with bortezomib, elicits eIF2- $\alpha$ phosphorylation. This finding suggests that the ability to induce eIF2- $\alpha$ phosphorylation is not a critical determinant for the apoptotic potential of agents that block proteasome function.
We previously showed that b-AP15 induces lysosomal membrane permeabilization and apoptosis dependent on the lysosomal protease cathepsin-D (4). Interestingly, several apoptotic agents have been described to trigger lysosomal membrane permeabilization and induce cell death by generating oxidative stress $(12,47,53,59)$. Although the precise mechanism is unclear, increased production of ROS may lead to destabilization
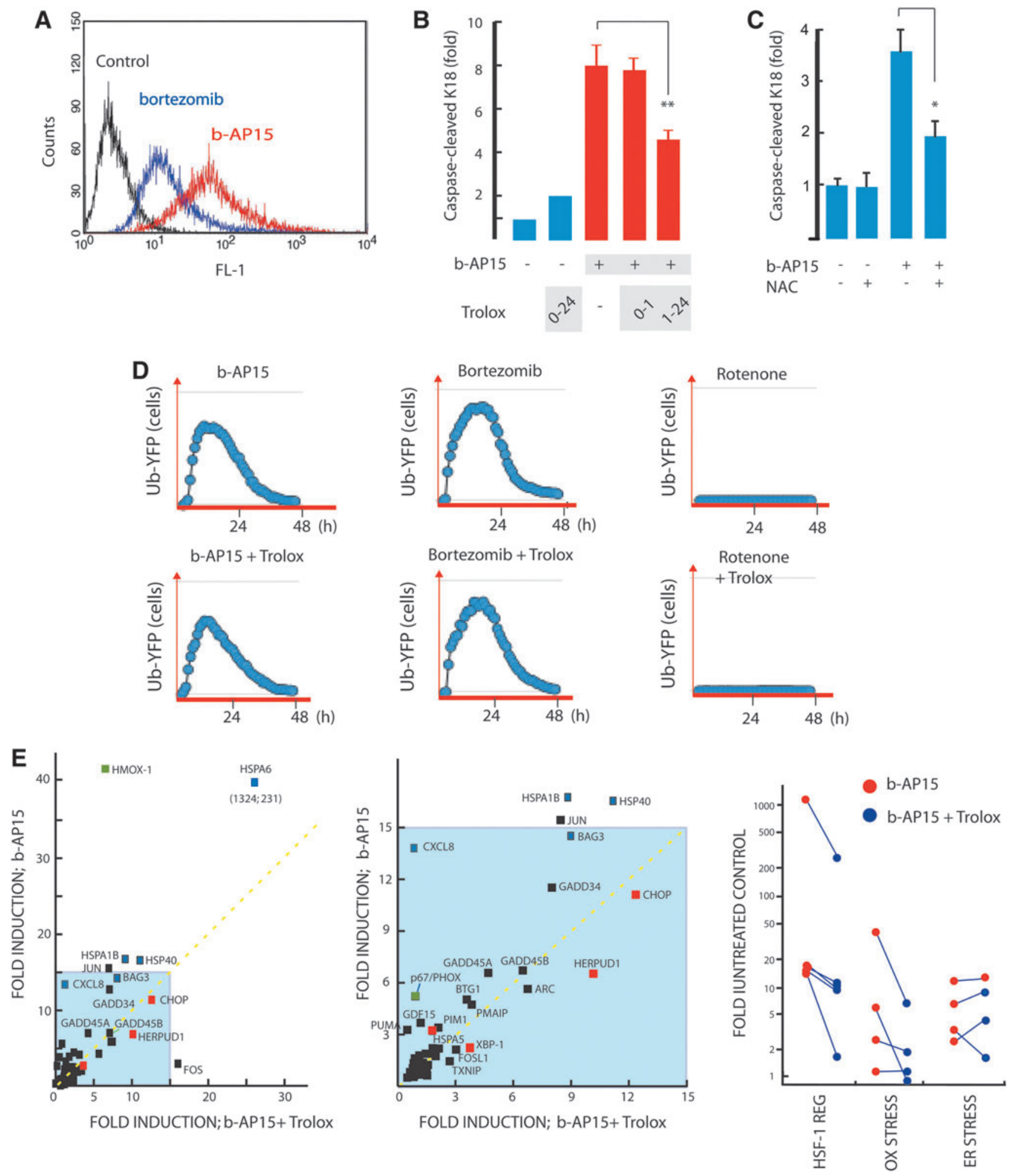


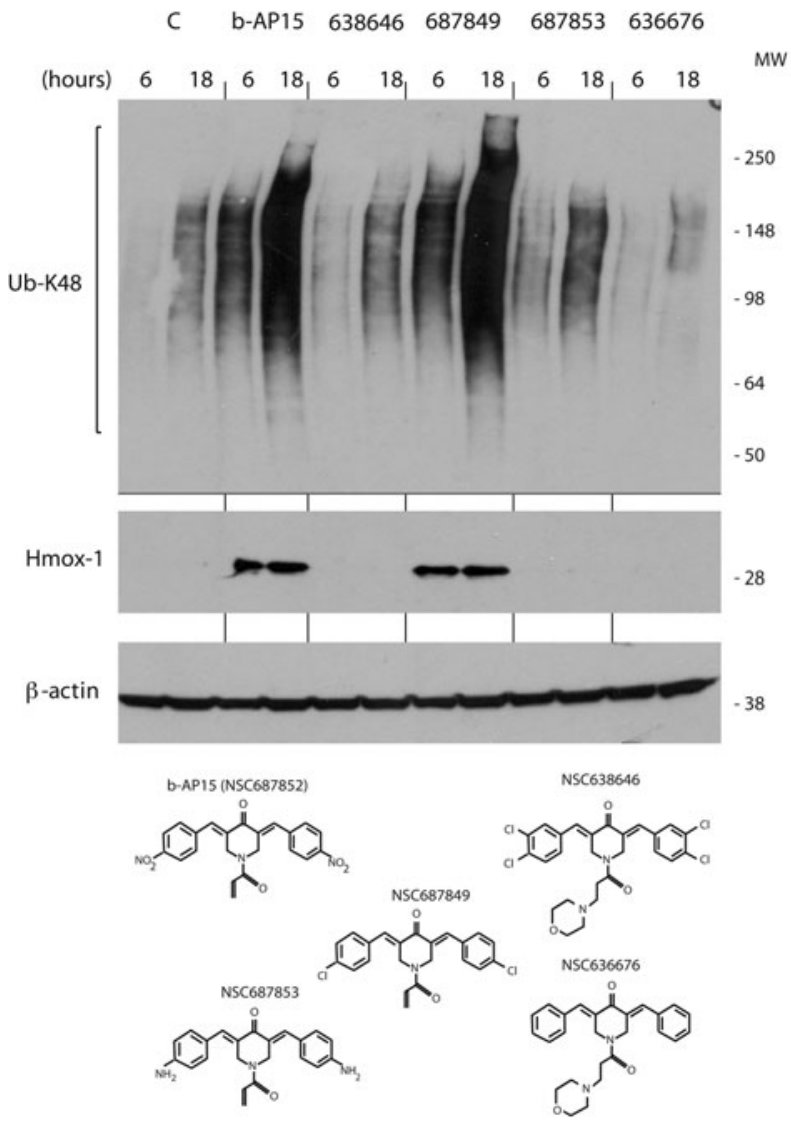

FIG. 6. Association between induction of Hmox-1 and accumulation of high-molecular-weight poly-ubiquitin. Cells were treated with the indicated compounds at a concentration of $1 \mu \mathrm{M}$. Cells were processed for western blotting using the indicated antibodies. Compounds were gifts from the National Cancer Institute; shown are cancer chemotherapy National Service Center numbers. Further information on these compounds is available using the search function at http://dtp.nci.nih.gov/dtpstandard/dwindex/index.jsp

of the lysosomal membrane via massive peroxidation of membrane lipids. The present observations of high levels of ROS induction by b-AP15 would be consistent with these results.

We conclude that the strong proapoptotic potential of the DUB inhibitor b-AP15 is associated with induction of oxida- tive stress. This is common territory in the field of cancer therapy, as, in fact, most of our clinically used cancer drugs, as well as ionizing radiation, induce oxidative stress (61). Malignant transformation is known to be associated with enhanced cellular stress, including both oxidative and proteotoxic stress, and the strong oxidative stress associated with b-AP15 may be poorly tolerated by cancer cells, providing a rational for therapy of a wide variety of malignancies $(38,57)$.

\section{Materials and Methods \\ Materials}

b-AP15 was obtained from Oncotargeting AB, bortezomib from ApoEx, SP600125 from Sigma-Aldrich, and SB203580 from Cell Signaling. Compounds were dissolved in dimethyl sulfoxide. Control cultures received the same final concentration of solvent as treated ones.

\section{Cell culture}

HCT116 colon carcinoma cells were maintained in McCoy's 5A modified medium $/ 10 \%$ fetal calf serum. The proteasome reporter cell line MelJuSo Ub-YFP was generated as described (40) and was cultured in Dulbecco's modified Eagle's medium $/ 10 \%$ fetal calf serum. All cells were maintained at $37^{\circ} \mathrm{C}$ in $5 \% \mathrm{CO}_{2}$ and subcultured by trypsinization.

\section{Assessment of apoptosis}

HCT116 cells were seeded in 96-well microtiter plates at 10,000 cells per well and incubated overnight. Drugs were then added and cells were incubated further. At the end of the incubation period, NP40 was added to the tissue culture medium to $0.1 \%$ and $25 \mu \mathrm{l}$ of the content of each well was assayed using the M30-CytoDeath ${ }^{\circledR}$ enzyme-linked immunosorbent assay (ELISA) (Peviva AB) (28). This ELISA is based on a specific antibody against a neoepitope of K18 that is generated by the action of caspase-3, -7- and -9 activated in response to apoptosis (34).

\section{Measurement of Bak-associated immunofluorescence}

Cells were fixed in paraformaldehyde $(0.25 \%, 5 \mathrm{~min})$ before incubation for $1 \mathrm{~h}$ with an antibody recognizing an $\mathrm{N}$-terminal

FIG. 7. b-AP15-induced apoptosis is dependent on activation of AP-1. (A, B) Gene set enrichment analysis based on bAP15 treatment of HCT116 cells ( $1 \mu \mathrm{M}, 6 \mathrm{~h}$ exposure). The genes have been rank ordered according to their relative expression after b-AP15 exposure compared with vehicle control. The enrichment profiles (green areas) show the enrichment of genes (represented by black vertical lines) containing binding sites for HSF-1 and AP-1, respectively. Nominal $p$-values $<0.001$; NES $=$ normalized enrichment score (54). (C) Induction of phosphorylation of JNK1/2 by b-AP15 (1 $\mu$ M) or bortezomib $(100 \mathrm{nM})$. HCT116 cells were exposed to the drugs for the indicated time in hours. Note the detection of JNK phosphorylation at 1 and $2 \mathrm{~h}$ of exposure to b-AP15, but not to bortezomib; (D) Induction of phosphorylation of JNK1/2 b-AP15, but not by bortezomib, at $2 \mathrm{~h}$ of drug exposure. HCT116 cells were exposed to the indicated concentration of drugs. (E) Induction of phosphorylation of c-Jun by b-AP15 $(1 \mu \mathrm{M})$ or bortezomib $(100 \mathrm{nM})$. HCT116 cells were exposed to the drugs for the indicated time in hours. (F) Induction of c-Jun phosphorylation by b-AP15 $(1 \mu M)$ or bortezomib $(100 \mathrm{nM})$ is inhibited by the JNK inhibitor SP600125 $(10 \mu M)$, but not by the p38-MAPK inhibitor SB203580 (10 $\mu \mathrm{M})$. HCT116 cells were treated for $6 \mathrm{~h}$. Note that c-Jun phosphorylation is inhibited by SP600125, whereas JNK phosphorylation is only marginally inhibited. (G) NAC ( $5 \mathrm{mM}$ ) inhibits b-AP15-induced phosphorylation of JNK. HCT116 cells were exposed to b-AP15 (1 $\mu$ M), followed by washout and addition of NAC. Numbers below the blots represent the p-JNK/JNK ratios. (H) The JNK inhibitor SP600125 inhibits bAP15-induced caspase-cleavage of K18. HCT116 cells were treated with $1 \mu M$ b-AP15 or $100 \mathrm{nM}$ bortezomib for $24 \mathrm{~h}$ in the presence or absence of $10 \mu \mathrm{M}$ SP600125. Caspase-cleaved K18 was determined by ELISA. AP-1, activating protein-1; JNK, Jun $\mathrm{N}$-terminal kinase. 
epitope of Bak that is accessible only after conformational activation (AM03; Oncogene Research Products) (17). The primary antibody was diluted in phosphate buffered saline (PBS) containing digitonin $(100 \mu \mathrm{g} / \mathrm{ml})$. Cells were then incubated for $1 \mathrm{~h}$ with an Allophycocyanin-conjugated secondary antibody in PBS (550826; BD Biosciences Pharmingen), and fluorescence was measured by flow cytometry.

\section{Measurement of DCFH-DA fluorescence}

HCT116 cells were treated with b-AP15, bortezomib, or solvent; stained using DCFH-DA; and subsequently analyzed using an FL1-H wavelength channel of a fluorecescenceactivated cell sorting (FACS) Calibur flow cytometer.

\section{siRNA knock-down}

HCT116 cells were transfected with siRNA (Qiagen) against human BAK, BAX, or a scrambled control sequence. Two days later, the transfected cells were trypsinized and seeded in 96-well plates. The day after seeding, drugs were added to the cells and drug treatment was allowed to continue for $24 \mathrm{~h}$, after which analysis of apoptosis using the M30Apoptosense ELISA was conducted.
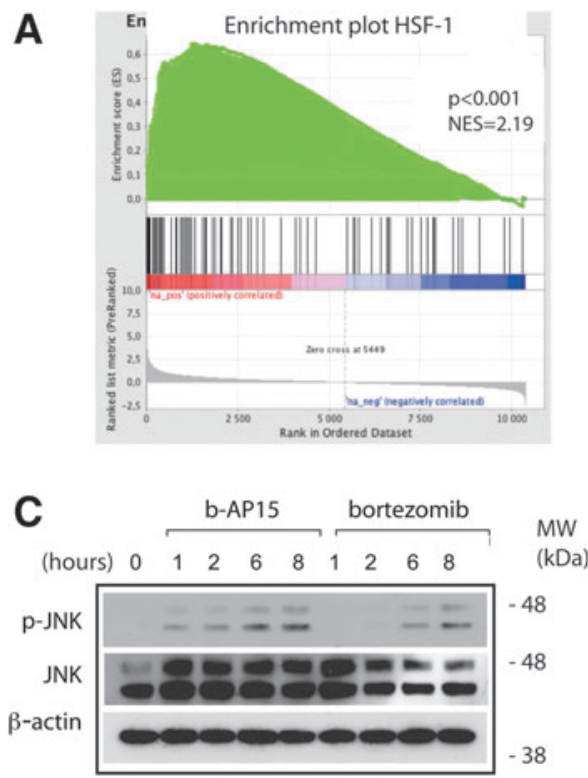

E

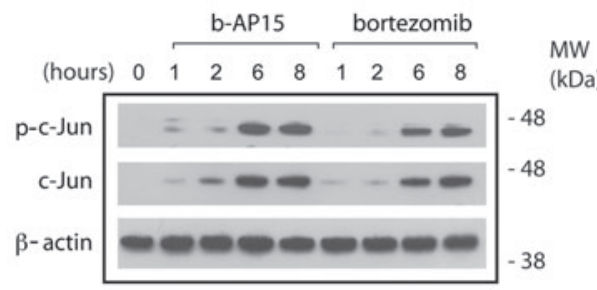

\section{G}

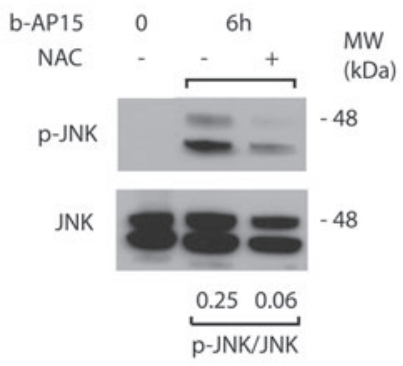

B

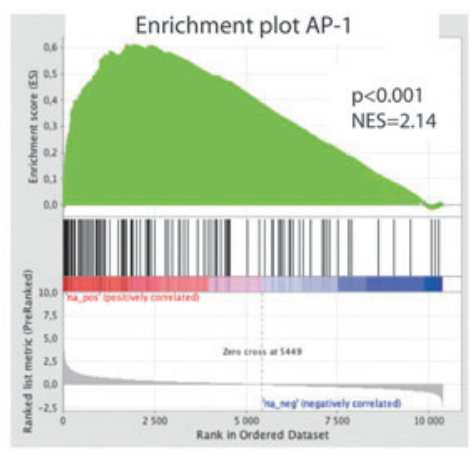

D

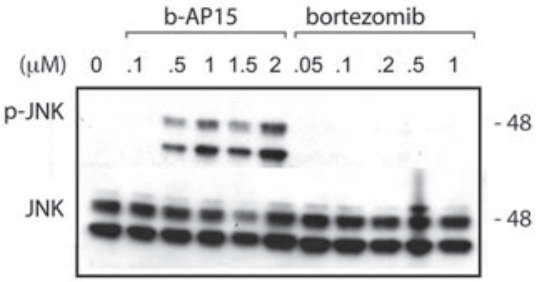

F

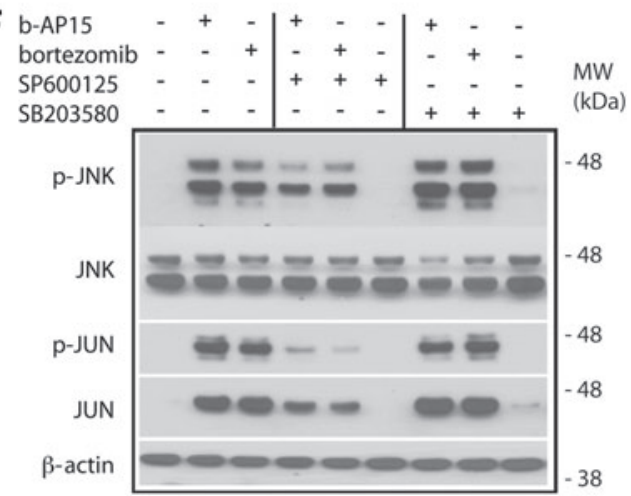

H

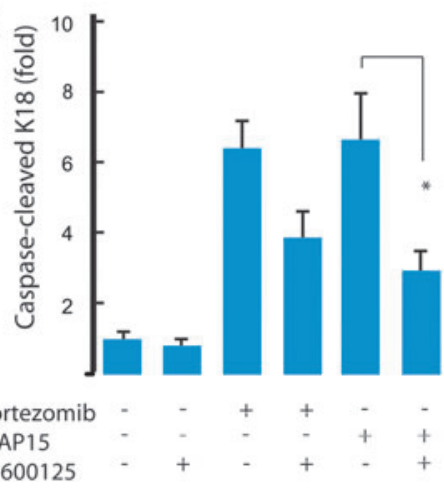




\section{Western blot analysis}

For ubiquitin analysis, cell extract proteins were resolved by Tris-Acetate polyacrylamide gel electrophoresis gels (Invitrogen) and transferred onto a polyvinylidene difluoride membrane for western blotting. Antibodies were obtained from the following sources: c-JUN (BD Transduction Laboratories), p-cJUN (Ser73), eIF2- $\alpha$, p-eIF2- $\alpha$ p-JNK (T183/Y185) (Cell Signaling), JNK (Santa Cruz), HMOX1, GRP78 (BD Transduction Laboratories), ubiquitin (Chemicon), and $\beta$-actin (Sigma-Aldrich).

\section{Live-cell analysis of UPS activity}

MelJuSo $\mathrm{Ub}^{\mathrm{G} 76 \mathrm{~V}}$-YFP cells (40) were plated in black optically clear bottom ViewPlates (PerkinElmer) overnight and then treated with b-AP15 or bortezomib. Treatment with compounds that block the UPS leads to accumulation of YFP in these cells, and the generated fluorescence was continuously detected in an IncuCyte FLR instrument (Essen BioScience Inc.).

\section{Transcriptional profiling and GSEA}

We examined the pattern of transcripts for 84 genes that were reported to respond to stress. The identity of these genes is given in Supplementary Table S1. Cells were exposed to $\mathrm{b}$-AP15 or bortezomib for $6 \mathrm{~h}$ in the presence of absence of Trolox; cDNA was prepared from $1 \mu \mathrm{g}$ of RNA using the $\mathrm{RT}^{2}$ First-Strand Kit (SA Biosciences). All primers used for qPCR were purchased from SA Biosciences Corp. The array analysis was carried out following the manufacturer's protocol with SYBR Green PCR (ROX) Master Mix (SA Biosciences Corp.). Arrays were assayed for 1 cycle of $10 \mathrm{~min}$ at $95^{\circ} \mathrm{C}$, then 40 cycles of $\left(15 \mathrm{~s}\right.$ at $95^{\circ} \mathrm{C}$, followed by $1 \mathrm{~min}$ at $\left.60^{\circ} \mathrm{C}\right)$ using an ABI7500 system. All conditions were performed in triplicate and normalized to five housekeeping gene mRNA levels. To analyze the PCR-array data, SA Biosciences Web-portal software was used: http://pcrdataanalysis.sabiosciences.com/ pcr/arrayanalysis.php

The GSEA software and method for microarray result exploration has been described elsewhere (54). Briefly, the preranked gene list from b-AP15 cells versus untreated control (10) was compared with a priori defined and curated gene sets from the MSigDB database (i.e., V\$AP1_01 with systematic name M10220 and V\$HSF_Q6 with systematic name M16482), using standard GSEA settings. The purpose of GSEA is to find out whether the a priori defined gene sets are significantly enriched toward the upper or lower end of the pre-ranked list. The $p$-value refers to the nominal $p$-values after 1000 permutations.

\section{Measurement of mitochondrial membrane potential}

Loss of mitochondrial membrane potential was assessed by incubating cells with $25 \mathrm{nM}$ TMRE (Invitrogen) for $30 \mathrm{~min}$. Changes in mitochondrial membrane potential $(\Delta \Psi)$ were monitored in an FACS Calibur flow cytometer.

\section{Statistical analysis}

Statistical analysis (Student's t-test, Pearson correlation coefficient, or Spearman's rank correlation coefficient, as indicated) was performed using Prism software for Apple computers. Statistical significance in t-test was plotted as follows: ${ }^{*}(p<0.05),{ }^{* *}(p<0.01)$, and ${ }^{* *}(p<0.001)$.

\section{Acknowledgments}

The authors acknowledge the Developmental Therapeutics Branch at the NCI, Bethesda, for supplying compounds. They are grateful to Maria Rydåker, Lena Lenhammar, and Christina Leek for excellent technical support. They also thank Stephan Feller, University of Oxford, for the gift of colon carcinoma cell lines. This work was supported by Cancerfonden, Radiumhemmets Forskningsfonder, Vetenskapsrådet, and Strategiska Forskningsstiftelsen (SSF).

\section{Author Disclosure Statement}

M.F., R.L., and S.L. own shares in Vivolux AB, which develops cancer drugs based on proteasomal inhibition. No competing financial interests exist for the other authors.

\section{References}

1. Adams J, Palombella VJ, Sausville EA, Johnson J, Destree A, Lazarus DD, Maas J, Pien CS, Prakash S, and Elliott PJ. Proteasome inhibitors: a novel class of potent and effective antitumor agents. Cancer Res 59: 2615-2622, 1999.

2. Aiken CT, Kaake RM, Wang X, and Huang L. Oxidative stress-mediated regulation of proteasome complexes. Mol Cell Proteomics 10: R110 006924, 2011.

3. Angel P, Hattori K, Smeal T, and Karin M. The jun protooncogene is positively autoregulated by its product, Jun/ AP-1. Cell 55: 875-885, 1988.

4. Berndtsson M, Beaujouin M, Rickardson L, Havelka AM, Larsson R, Westman J, Liaudet-Coopman E, and Linder S. Induction of the lysosomal apoptosis pathway by inhibitors of the ubiquitin-proteasome system. Int J Cancer 124: 14631469, 2009.

5. Breitschopf K, Zeiher AM, and Dimmeler S. Ubiquitinmediated degradation of the proapoptotic active form of bid: a functional consequence on apoptosis induction. J Biol Chem 275: 21648-21652, 2000.

6. Caravita T, de Fabritiis P, Palumbo A, Amadori S, and Boccadoro M. Bortezomib: efficacy comparisons in solid tumors and hematologic malignancies. Nat Clin Pract Oncol 3: 374-387, 2006.

7. Chen S, Blank JL, Peters T, Liu XJ, Rappoli DM, Pickard MD, Menon S, Yu J, Driscoll DL, Lingaraj T, Burkhardt AL, Chen W, Garcia K, Sappal DS, Gray J, Hales P, Leroy PJ, Ringeling J, Rabino C, Spelman JJ, Morgenstern JP, and Lightcap ES. Genome-wide siRNA screen for modulators of cell death induced by proteasome inhibitor bortezomib. Cancer Res 70: 4318-4326, 2010.

8. Cohen $\mathrm{P}$, and Tcherpakov M. Will the ubiquitin system furnish as many drug targets as protein kinases? Cell 143: 686-693, 2010.

9. Cotto-Rios XM, Bekes M, Chapman J, Ueberheide B, and Huang TT. Deubiquitinases as a signaling target of oxidative stress. Cell Rep 2: 1475-1484, 2012.

10. D'Arcy P, Brnjic S, Olofsson MH, Fryknas M, Lindsten K, De Cesare M, Perego P, Sadeghi B, Hassan M, Larsson R, and Linder S. Inhibition of proteasome deubiquitinating activity as a new cancer therapy. Nat Med 17: 1636-1640, 2011.

11. Davenport EL, Moore HE, Dunlop AS, Sharp SY, Workman P, Morgan GJ, and Davies FE. Heat shock protein inhibition is associated with activation of the unfolded protein 
response pathway in myeloma plasma cells. Blood 110: 26412649, 2007.

12. De Milito A, Iessi E, Logozzi M, Lozupone F, Spada M, Marino ML, Federici C, Perdicchio M, Matarrese P, Lugini L, Nilsson A, and Fais S. Proton pump inhibitors induce apoptosis of human B-cell tumors through a caspase-independent mechanism involving reactive oxygen species. Cancer Res 67: 5408-5417, 2007.

13. Fernandes AF, Zhou J, Zhang X, Bian Q, Sparrow J, Taylor A, Pereira P, and Shang F. Oxidative inactivation of the proteasome in retinal pigment epithelial cells: a potential link between oxidative stress and up-regulation of interleukin-8. J Biol Chem 283: 20745-20753, 2008.

14. Fernandez Y, Miller TP, Denoyelle C, Esteban JA, Tang WH, Bengston AL, and Soengas MS. Chemical blockage of the proteasome inhibitory function of bortezomib: impact on tumor cell death. J Biol Chem 281: 1107-1118, 2006.

15. Fribley A, Zeng Q, and Wang CY. Proteasome inhibitor PS-341 induces apoptosis through induction of endoplasmic reticulum stress-reactive oxygen species in head and neck squamous cell carcinoma cells. Mol Cell Biol 24: 9695-9704, 2004.

15a. Friedrich J, Eder W, Castaneda J, Doss M, Huber E, Ebner R, and Kunz-Schughart LA. A reliable tool to determine cell viability in complex 3-d culture: the acid phosphatase assay. J Biomol Screen 12: 925-937, 2007.

16. Fujino G, Noguchi T, Matsuzawa A, Yamauchi S, Saitoh M, Takeda $\mathrm{K}$, and Ichijo $\mathrm{H}$. Thioredoxin and TRAF family proteins regulate reactive oxygen species-dependent activation of ASK1 through reciprocal modulation of the N-terminal homophilic interaction of ASK1. Mol Cell Biol 27: 8152-8163, 2007.

17. Griffiths GJ, Dubrez L, Morgan CP, Jones NA, Whitehouse J, Corfe BM, Dive C, and Hickman JA. Cell damage-induced conformational changes of the pro-apoptotic protein Bak in vivo precede the onset of apoptosis. J Cell Biol 144: 903-914, 1999.

18. Groll M, Heinemeyer W, Jager S, Ullrich T, Bochtler M, Wolf $\mathrm{DH}$, and Huber $\mathrm{R}$. The catalytic sites of $20 \mathrm{~S}$ proteasomes and their role in subunit maturation: a mutational and crystallographic study. Proc Natl Acad Sci U S A 96: 10976-10983, 1999.

19. Halasi M, Wang M, Chavan TS, Gaponenko V, Hay N, and Gartel AL. ROS inhibitor N-acetyl-L-cysteine antagonizes the activity of proteasome inhibitors. Biochem J 454: 201-208, 2013.

20. Hamanaka RB, Bennett BS, Cullinan SB, and Diehl JA. PERK and GCN2 contribute to eIF2alpha phosphorylation and cell cycle arrest after activation of the unfolded protein response pathway. Mol Biol Cell 16: 5493-5501, 2005.

21. Hanna J, Hathaway NA, Tone Y, Crosas B, Elsasser S, Kirkpatrick DS, Leggett DS, Gygi SP, King RW, and Finley D. Deubiquitinating enzyme Ubp6 functions noncatalytically to delay proteasomal degradation. Cell 127: 99-111, 2006.

22. Harding HP, Zhang Y, Bertolotti A, Zeng H, and Ron D. Perk is essential for translational regulation and cell survival during the unfolded protein response. Mol Cells 5: 897-904, 2000.

23. Hershko A, and Ciechanover A. The ubiquitin system. Annu Rev Biochem 67: 425-479, 1998.

24. Hideshima T, Chauhan D, Richardson P, Mitsiades C, Mitsiades N, Hayashi T, Munshi N, Dang L, Castro A, Palombella V, Adams J, and Anderson KC. NF-kappa B as a therapeutic target in multiple myeloma. J Biol Chem 277: 16639-16647, 2002.

25. Hideshima T, Mitsiades C, Akiyama M, Hayashi T, Chauhan D, Richardson P, Schlossman R, Podar K, Munshi NC, Mitsiades N, and Anderson KC. Molecular mechanisms mediating antimyeloma activity of proteasome inhibitor PS341. Blood 101: 1530-1534, 2003.
26. Hitomi J, Katayama T, Eguchi $\mathrm{Y}$, Kudo T, Taniguchi $\mathrm{M}$, Koyama Y, Manabe T, Yamagishi S, Bando Y, Imaizumi K, Tsujimoto $Y$, and Tohyama M. Involvement of caspase-4 in endoplasmic reticulum stress-induced apoptosis and Abetainduced cell death. J Cell Biol 165: 347-356, 2004.

27. Huang R, Wallqvist A, Thanki N, and Covell DG. Linking pathway gene expressions to the growth inhibition response from the National Cancer Institute's anticancer screen and drug mechanism of action. Pharmacogenomics J 5: 381-399, 2005.

28. Hägg $M$, Biven $K$, Ueno $T$, Rydlander L, Björklund $P$, Wiman KG, Shoshan M, and Linder S. A novel high-throughput assay for screening of pro-apoptotic drugs. Invest New Drugs 20: 253-259, 2002.

29. Ichijo H, Nishida E, Irie K, ten Dijke P, Saitoh M, Moriguchi T, Takagi M, Matsumoto K, Miyazono K, and Gotoh Y. Induction of apoptosis by ASK1, a mammalian MAPKKK that activates SAPK/JNK and p38 signaling pathways. Science 275: 90-94, 1997.

30. Jarvius M, Fryknas M, D'Arcy P, Sun C, Rickardson L, Gullbo J, Haglund C, Nygren P, Linder S, and Larsson R. Piperlongumine induces inhibition of the ubiquitin-proteasome system in cancer cells. Biochem Biophys Res Commun 431: 117-123, 2013.

31. Kaufman RJ. Stress signaling from the lumen of the endoplasmic reticulum: coordination of gene transcriptional and translational controls. Genes Dev 13: 1211-1233, 1999.

32. Koulich E, Li X, and DeMartino GN. Relative structural and functional roles of multiple deubiquitylating proteins associated with mammalian 26S proteasome. Mol Biol Cell 19: 1072-1082, 2008.

33. Lee MJ, Lee BH, Hanna J, King RW, and Finley D. Trimming of ubiquitin chains by proteasome-associated deubiquitinating enzymes. Mol Cell Proteomics 10: R110 003871, 2011.

34. Leers MP, Kolgen W, Björklund V, Bergman T, Tribbick G, Persson B, Björklund P, Ramaekers FC, Björklund B, Nap M, Jörnvall $\mathrm{H}$, and Schutte B. Immunocytochemical detection and mapping of a cytokeratin 18 neo-epitope exposed during early apoptosis. J Pathol 187: 567-572, 1999.

35. Li B, and Dou QP. Bax degradation by the ubiquitin/ proteasome-dependent pathway: involvement in tumor survival and progression. Proc Natl Acad Sci U S A 97: 3850$3855,2000$.

36. Ling YH, Liebes L, Zou Y, and Perez-Soler R. Reactive oxygen species generation and mitochondrial dysfunction in the apoptotic response to Bortezomib, a novel proteasome inhibitor, in human H460 non-small cell lung cancer cells. J Biol Chem 278: 33714-33723, 2003.

37. Llobet D, Eritja N, Encinas M, Sorolla A, Yeramian A, Schoenenberger JA, Llombart-Cussac A, Marti RM, MatiasGuiu X, and Dolcet X. Antioxidants block proteasome inhibitor function in endometrial carcinoma cells. Anticancer Drugs 19: 115-124, 2008.

38. Luo J, Solimini NL, and Elledge SJ. Principles of cancer therapy: oncogene and non-oncogene addiction. Cell 136: 823-837, 2009.

39. Madamanchi NR, Li S, Patterson C, and Runge MS. Reactive oxygen species regulate heat-shock protein 70 via the JAK/ STAT pathway. Arterioscler Thromb Vasc Biol 21:321-326, 2001.

40. Menendez-Benito V, Verhoef LG, Masucci MG, and Dantuma NP. Endoplasmic reticulum stress compromises the ubiquitinproteasome system. Hum Mol Genet 14: 2787-2799, 2005.

41. Mialki RK, Zhao J, Wei J, Mallampalli DF, and Zhao Y. Overexpression of USP14 protease reduces I-kappaB protein levels and increases cytokine release in lung epithelial cells. $J$ Biol Chem 288: 15437-15441, 2013. 
42. Morse D, and Choi AM. Heme oxygenase-1: from bench to bedside. Am J Respir Crit Care Med 172: 660-670, 2005.

43. Nakagawa T, Zhu H, Morishima N, Li E, Xu J, Yankner BA, and Yuan J. Caspase-12 mediates endoplasmic-reticulumspecific apoptosis and cytotoxicity by amyloid-beta. Nature 403: 98-103, 2000.

44. Nawrocki ST, Carew JS, Dunner K, Jr., Boise LH, Chiao PJ, Huang P, Abbruzzese JL, and McConkey DJ. Bortezomib inhibits PKR-like endoplasmic reticulum (ER) kinase and induces apoptosis via ER stress in human pancreatic cancer cells. Cancer Res 65: 11510-11519, 2005.

45. Nikiforov MA, Riblett M, Tang WH, Gratchouck V, Zhuang D, Fernandez Y, Verhaegen M, Varambally S, Chinnaiyan AM, Jakubowiak AJ, and Soengas MS. Tumor cell-selective regulation of NOXA by c-MYC in response to proteasome inhibition. Proc Natl Acad Sci U S A 104: 19488-19493, 2007.

46. Noonan EJ, Place RF, Giardina C, and Hightower LE. Hsp70B' regulation and function. Cell Stress Chaperones 12: 393-402, 2007.

47. Ostenfeld MS, Fehrenbacher N, Hoyer-Hansen M, Thomsen C, Farkas T, and Jaattela M. Effective tumor cell death by sigma-2 receptor ligand siramesine involves lysosomal leakage and oxidative stress. Cancer Res 65: 8975-8983, 2005.

48. Penney M, Samejima I, Wilkinson CR, McInerny CJ, Mathiassen SG, Wallace M, Toda T, Hartmann-Petersen R, and Gordon C. Fission yeast 26S proteasome mutants are multidrug resistant due to stabilization of the Pap1 transcription factor. PLoS One 7: e50796, 2012.

49. Perez-Galan P, Roue G, Villamor N, Montserrat E, Campo E, and Colomer D. The proteasome inhibitor bortezomib induces apoptosis in mantle-cell lymphoma through generation of ROS and Noxa activation independent of p53 status. Blood 107: 257-264, 2006.

50. Peth A, Besche HC, and Goldberg AL. Ubiquitinated proteins activate the proteasome by binding to Usp14/Ubp6, which causes 20S gate opening. Mol Cells 36: 794-804, 2009.

51. Peth A, Kukushkin N, Bosse M, and Goldberg AL. Ubiquitinated proteins activate the proteasomal ATPases by binding to Usp14 or Uch37 homologs. J Biol Chem 288: 7781-7790, 2013.

52. Rabow AA, Shoemaker RH, Sausville EA, and Covell DG. Mining the National Cancer Institute's tumor-screening database: identification of compounds with similar cellular activities. J Med Chem 45: 818-840, 2002.

53. Roberg K, and Öllinger K. Oxidative stress causes relocation of the lysosomal enzyme cathepsin D with ensuing apoptosis in neonatal rat cardiomyocytes. Am J Pathol 152: 1151-1156, 1998.

54. Subramanian A, Tamayo P, Mootha VK, Mukherjee S, Ebert BL, Gillette MA, Paulovich A, Pomeroy SL, Golub TR, Lander ES, and Mesirov JP. Gene set enrichment analysis: a knowledge-based approach for interpreting genome-wide expression profiles. Proc Natl Acad Sci U S A 102: 15545-15550, 2005.

55. Sunwoo JB, Chen Z, Dong G, Yeh N, Crowl Bancroft C, Sausville E, Adams J, Elliott P, and Van Waes C. Novel proteasome inhibitor PS-341 inhibits activation of nuclear factorkappa B, cell survival, tumor growth, and angiogenesis in squamous cell carcinoma. Clin Cancer Res 7: 1419-1428, 2001.

56. Suraweera A, Munch C, Hanssum A, and Bertolotti A. Failure of amino acid homeostasis causes cell death following proteasome inhibition. Mol Cells 48: 242-253, 2012.

57. Trachootham D, Alexandre J, and Huang P. Targeting cancer cells by ROS-mediated mechanisms: a radical therapeutic approach? Nat Rev Drug Discov 8: 579-591, 2009.

58. Velentzas PD, Velentzas AD, Mpakou VE, Antonelou MH, Margaritis LH, Papassideri IS, and Stravopodis DJ. Detri- mental effects of proteasome inhibition activity in Drosophila melanogaster: implication of ER stress, autophagy, and apoptosis. Cell Biol Toxicol 29: 13-37, 2013.

59. Vene R, Arena G, Poggi A, D'Arrigo C, Mormino M, Noonan DM, Albini A, and Tosetti F. Novel cell death pathways induced by $\mathrm{N}$-(4-hydroxyphenyl)retinamide: therapeutic implications. Mol Cancer Ther 6: 286-298, 2007.

60. Verma R, Aravind L, Oania R, McDonald WH, Yates JR, 3rd, Koonin EV, and Deshaies RJ. Role of Rpn11 metalloprotease in deubiquitination and degradation by the $26 \mathrm{~S}$ proteasome. Science 298: 611-615, 2002.

61. Watson J. Oxidants, antioxidants and the current incurability of metastatic cancers. Open Biol 3: 120144, 2013.

62. Wei MC, Zong WX, Cheng EH, Lindsten T, Panoutsakopoulou V, Ross AJ, Roth KA, MacGregor GR, Thompson CB, and Korsmeyer SJ. Proapoptotic BAX and BAK: a requisite gateway to mitochondrial dysfunction and death. Science 292: 727-730, 2001.

63. Williams SA, and McConkey DJ. The proteasome inhibitor bortezomib stabilizes a novel active form of p53 in human LNCaP-Pro5 prostate cancer cells. Cancer Res 63: 7338-7344, 2003.

64. Yao T, and Cohen RS. A cryptic protease couples deubiquitinylation and degradation by the proteasome. Nature 419: 403-407, 2002.

65. Yu C, Rahmani M, Dent P, and Grant S. The hierarchical relationship between MAPK signaling and ROS generation in human leukemia cells undergoing apoptosis in response to the proteasome inhibitor Bortezomib. Exp Cell Res 295: 555-566, 2004.

66. Zhang X, Zhou J, Fernandes AF, Sparrow JR, Pereira P, Taylor A, and Shang F. The proteasome: a target of oxidative damage in cultured human retina pigment epithelial cells. Invest Ophthalmol Vis Sci 49: 3622-3630, 2008.

67. Zong ZH, Du ZX, Li N, Li C, Zhang Q, Liu BQ, Guan Y, and Wang HQ. Implication of Nrf2 and ATF4 in differential induction of $\mathrm{CHOP}$ by proteasome inhibition in thyroid cancer cells. Biochim Biophys Acta 1823: 1395-1404, 2012.

68. Zou W, Yue P, Lin N, He M, Zhou Z, Lonial S, Khuri FR, Wang B, and Sun SY. Vitamin C inactivates the proteasome inhibitor PS-341 in human cancer cells. Clin Cancer Res 12: 273-280, 2006.

Address correspondence to: Dr. Stig Linder

Department of Oncology and Pathology Karolinska Institute S-171 76 Stockholm Sweden

E-mail: Stig.Linder@ki.se

Dr. Pádraig D'Arcy Department of Oncology and Pathology Karolinska Institute S-171 76 Stockholm

Sweden

E-mail: Padraig.Darcy@ki.se

Date of first submission to ARS Central, March 19, 2013; date of final revised submission, August 21, 2013; date of acceptance, September 7, 2013. 

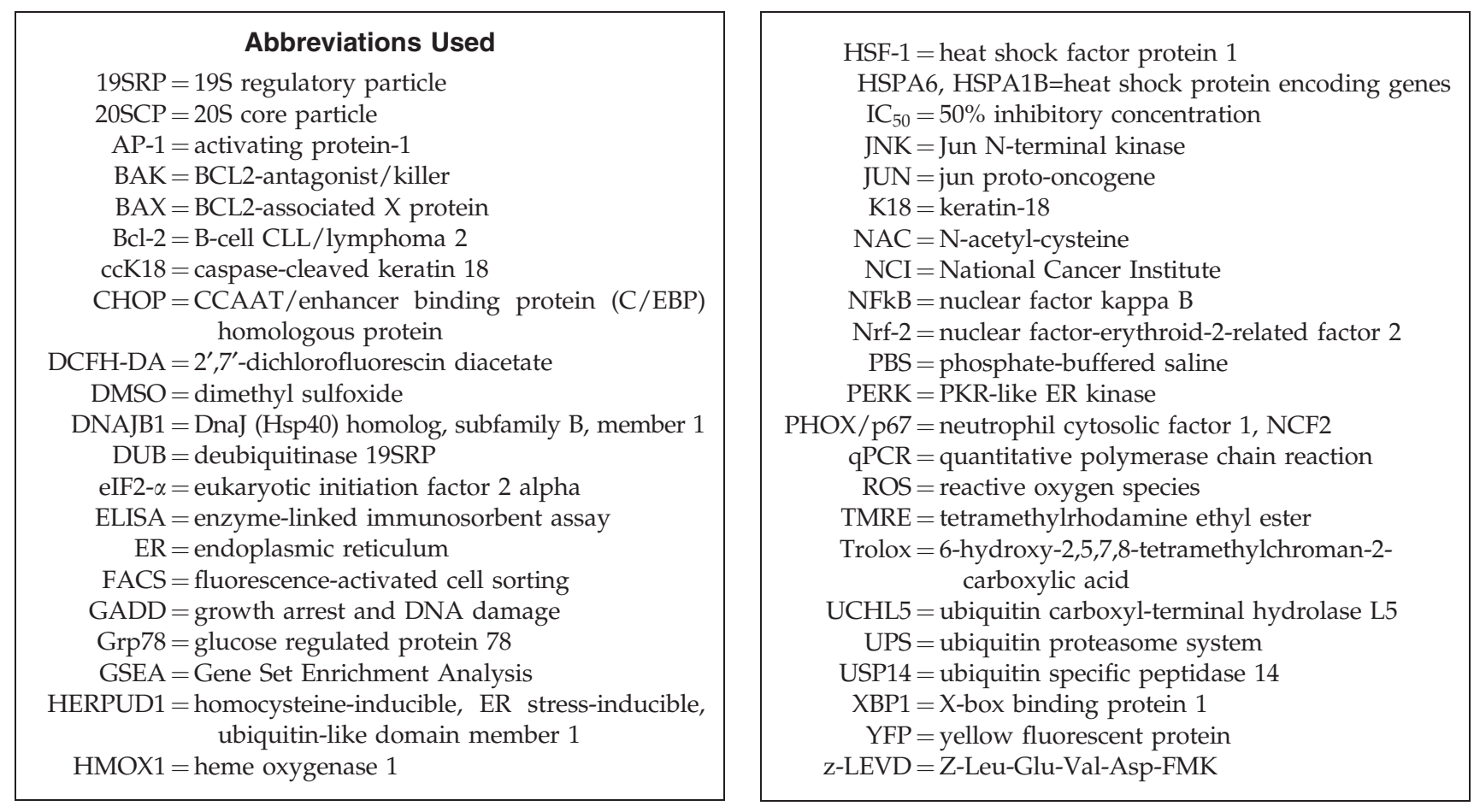